\title{
A Comparative Study of Pulmonary Functions in Patients with Type 2 Diabetes Mellitus and Normal Individuals
}

\author{
Dr. Rajesh Gautam
}

\author{
Assistant Professor, Department of Physiology, Prathima Institute of Medical Sciences, Naganoor, \\ Karimnagar,
}

Address for correspondence:Dr. Rajesh Gautam, H.No 65, Pocket F-17, Sector 8, Rohini, Behind Hanuman
Mandir, New Delhi 110085. Email: drgautam1282@gmail.com

DOI:10.47799/pimr.0901.12

Date of receiving: $24-02-2021$

Date of peer review: 1-03-2021

Date of Acceptance: 02-03-2021

\begin{abstract}
:
Background: Diabetes mellitus is a multi-system disorder that affects many organs of the bodyincluding the lung. Thus, the lung is considered a 'target organ' in diabetes mellitus. Thepresent study is undertaken to evaluate the impact of type 2 diabetes mellitus onpulmonary functions of adult male diabetic patients and to compare between type 2diabetes mellitus patients and healthy adult male subjects.
\end{abstract}

Methods: Hundred adult male type 2 diabetic patients were selected from the diabetic clinic,

Prathima Institute of Medical Sciences, Nagunur, Karimnagar, and 100 adult male healthy subjects were selected randomly among the general population from Karimnagar city. spirograms were recorded by Spirowin PC-basedSpirometer. Parameters such as Forced Vital Capacity (FVC), Forced ExpiratoryVolume in 1st second (FEV1), the ratio of FEV1/FVC, Forced Expiratory Flow (FEF) inthe Middle Half of FVC, and Peak Expiratory Rate (PEFR) were assessed and analyzedby using the paired t-test and ANOVA.

Results: Diabetes mellitus has a negative impact on pulmonary functions when compared with healthy subjects. In this study type 2 diabetes mellitus patients showed a significantly greater percentage decline in FVC, FEV1, FEF25-75\%, PEFR, and a slight increase in the ratio of FEV1/FVC suggestive of the restrictive pulmonary disorder.

\section{Conclusion:}

This study found the pulmonary functions FVC, FEV1, FEF25\%-75\%, and PEFR are decreased inType 2 diabetes mellitus compared to controls. FEV1/FVC\% slightly increased in Type 2 diabetes mellitus, which is indicative of the restrictive pulmonary disorder.
Keywords: Diabetes Mellitus, Pulmonary Function Tests, Spirometer

\section{Introduction}

Diabetes mellitus is a disease known since the time a very long time. Ancient Indian scholars like Charaka and Shushrutha have described it. ${ }^{[1]}$ It is characterized by hyperglycemia resulting from absolute or relative insulin secretion or both. Based on this, it is has been classified as type I (Insulin Dependent) and Type 2(Insulin Independent). In type In Type 1, there is an absolute deficiency of insulin secretion. In Type 2, the form driving the current epidemic of diabetes results from a combination of pancreatic beta-cell secretion and peripheral tissue resistance to the actions of insulin. Insulin resistance results from genetic factors, decreased physical activity, aging, and obesity. ${ }^{[2,3]}$ Diabetes mellitus isaccompanied by widespread biochemical, morphological, and functional abnormalities which may precipitate certain complications such asrenal, cardiovascular, neural systems, skin, liver, collagen, and elastic fibers. ${ }^{[4]}$ Diabetes mellitus is a known risk factor for microvascularpathologies leading to autonomic neuropathy, nephropathy, retinopathy, peripheralneuropathy, and macrovascular pathologies leading to coronary artery disease,cerebrovascular accidents, and peripheral vascular disease. The microvascularcomplications appear early, within 5 to $10 y r s$ and macrovascularcomplications appear within 15 to $20 y$ rs from the onset of diabetes. If diabetesmellitus is detected early and adequate steps are taken, it can be possible tosignificantly delay the occurrence of complications and thereafter the progression. ${ }^{[5]}$ Lungs are particularly affected in long-standing diabetics due to thickened alveolar epithelial cells and pulmonary capillary basal lamina leading to reduced pulmonary elastic recoiling of lung tissue. This leads to impaired 
diffusion of gases due to reduced capillary volume and decreased perfusion. Nonenzymatic glycosylation induces alteration of lung connective tissue is the most likely mechanism underlying the mechanical pulmonary dysfunction in diabetic subjects. This suggests that the lung is one of the 'target organs' in diabetes mellitus. ${ }^{[6]}$ Although pulmonary functions in diabetics are impaired to a certain extent the results are not so exclusively documented hence we in the study tried to evaluate the impact of type 2 diabetes mellitus on pulmonary functions and compare with the results of aged and sex-matched normal controls.

\section{Material and methods}

The present study was conducted in the Department of Physiology, Prathimalnstitute of Medical Sciences, Nagunur, Karimnagar. Institutional Ethical committee permission was obtained for this study. Written consent was obtained from all the participants of the study. The study was undertaken to observe the effects of type 2 diabetes mellitus (T2DM) on the pulmonary functions of adult male subjects of age group 4055 years. The pulmonary functions of adult male T2DM patients were compared with the healthy adult male healthy subjects.

\section{Inclusion criteria}

1. Adult male with type II diabetes mellitus aged $40-55$ years

2. No history of significant lung diseases

3. Age and sex-matched normal as controls

4. Those willing to participate in the study voluntarily.

\section{Exclusion criteria}

1. Those with type II DM but not in the required age group

2. With a history of smoking, pulmonary diseases

\section{With a history of cardiovascular diseases}

4. Female cases

A total of $n=100$ cases were selected in the study group and $n=100100$ healthy male subjects wereselected randomly among the general population of Karimnagar city as controls. The selected cases were then recorded with brief personal history, smoking history, and a clinical examination of all the systems was done to exclude medical problemsand to prevent confounding of the result. The fasting blood sugar (FBS) and postprandialblood sugar (PPBS) are done on the same day of pulmonary function tests in the centrallab Prathima Hospital, Karimnagar.The pulmonary functions of all the subjects were done in the morning session(between $11 \mathrm{am}$ to $1 \mathrm{pm}$ ) of the college hours. The physical characters such as heightin centimeters and weight in kilograms of all the subjects were recorded and uploaded on the computer to get predicted values for pulmonary function tests. All this personal information like age, sex, and a brief history were entered inthe patient information chart giving a separate ID for each subject.We used Spirowin PC-based Spirometerfor assessing the pulmonaryfunctions. This Spirometer has a mouthpiece attached to a transducer assembly which isconnected to an adaptor box and this is connected to the computer by a serial cable. Software from the Recorders and Medicare system is loaded onto the computer. Thissoftware allows the calculation of the predicted values for age, sex, weight, and heightand it also gives the recorded values of all the parameters.Subjects were motivated before the start of the maneuver. The subjects weremade to sit on a stool, then place the mouthpiece firmly in mouth, ask the subject totake a maximum inspiration and then we would attach a nose clip and ask him toexecute a maximum forced expiration with full efforts, and this is followed by amaximum forced inspiration.The test was performed over 3 maneuvers. The tests with the best maneuverwere selected. The machine gives us the comparison of various parameters between the 3maneuvers and we accepted the best maneuver.The results for each parameter were compared between type 2 diabetesmellitus patients and the healthy adult male controls and statistically analyzed.Statistical analysis of data Mean ? Standard Deviation and range values. Comparisons were performed using students t-test for 2 group comparisons and one-way ANOVA for multiple groups. The $p$ value of 0.05 or less was considered as statistical significance.

\section{Results}

The age of the subjects in the study ranged between 40-55 years. They weregrouped into type $2 \mathrm{DM}$ patients and healthy adult male controls. Out of the hundred cases of type 2 DM patients $n=25$ patients were in the age group of $40-44$ years, $n=23$ was in the age group of $45-49$ years, and $n=52$ were in the age group of50-55 years. Out of the hundred healthy adult male controls $n=33$ was in the age group of $40-44$ years, $n=26$ was in the age group of $45-49$ years and $n=41$ was in the age group of 50-55 years. On analysing the basic characteristics of the 100 type 2 DM patients the meanage (in yrs) is 48.8 \pm 5.2 ; the mean height (in $\mathrm{cm}$ ) is $165.3+8.4$; the mean weight $(\mathrm{Kg}$ ) is $66.21 \pm 10.85$ and mean BSA (in $\mathrm{m} 2$ ) is $1.75 \pm 0.16$, the mean BMI ( $\mathrm{kg} / \mathrm{m} 2)$ is $24.22 \pm 3.64$ the mean FBS $(\mathrm{mg} / \mathrm{dl})$ is 174.5 \pm 66.1 and the mean PPBS $(\mathrm{mg} / \mathrm{dl})$ is $293.3 \pm 89.7$ (Table 1)

Table 1: Comparison of variables between the study and control group 


\begin{tabular}{|c|c|c|c|c|}
\hline \multirow{2}{*}{ Variable } & \multirow{2}{*}{ Type 2 DM cases $(n=100)$} & \multirow{2}{*}{ Control $(n=100)$} & \multicolumn{2}{|c|}{ Significance } \\
\cline { 4 - 5 } & $48.8 \pm 5.2$ & $47.7 \pm 5.15$ & 1.52 & 0.13 \\
\hline Age in years & $165.3 \pm 8.4$ & $165.4 \pm 7.9$ & 0.10 & 0.94 \\
\hline Height in cms & $66.21 \pm 10.85$ & $63.79 \pm 9.49$ & 1.68 & 0.10 \\
\hline Weight in Kgs & $1.75 \pm 0.16$ & $1.72 \pm 0.15$ & 1.28 & 0.20 \\
\hline BSA in m2 & $24.22 \pm 3.64$ & $23.32 \pm 2.96$ & 1.93 & 0.06 \\
\hline BMI (Kg/m2) & $174.5 \pm 66.1$ & $84.1 \pm 7.7$ & 13.58 & 0.001 \\
\hline FBS (mgl/dl) & $293.3 \pm 89.7$ & $123.9 \pm 7.4$ & 18.52 & 0.001 \\
\hline PPBS (mg/dl) & & & & $\mathrm{t}$ \\
\hline
\end{tabular}

FVC:The Actual Value of FVC (L) in type 2 DM patients was $2.35 \pm 0.68$ (70.5 $\pm 15.8 \%$ of percentage predicted). The Actual Value of FVC $(L)$ in controls was $3.16 \pm 0.40$ (92.5 $\pm 7.2 \%$ of percentage predicted). There was a statistically significantdecrease in the level of FVC in type $2 \mathrm{DM}$ patients compared to healthy adult malecontrols $(p<0.001)$ (Table 2)

Table 2: comparison of FVC between type 2 diabetes mellitus patients and controls

\begin{tabular}{|c|c|c|c|c|c|}
\hline \multirow{2}{*}{ Groups } & \multirow{2}{*}{$\mathrm{n}$} & \multicolumn{2}{|c|}{ Actual range } & \multicolumn{2}{c|}{ Predicted (\%) } \\
\cline { 3 - 6 } & & Range & Mean \pm SD & Range & Mean \pm SD \\
\hline Type 2 DM & 100 & $1.22-4.25$ & $2.35 \pm 0.68$ & $36-121$ & $70.5 \pm 15.8$ \\
\hline Controls & 100 & $2.08-4.10$ & $3.16 \pm 0.40$ & $75-114$ & $92.5 \pm 7.2$ \\
\hline Mean difference & & \multicolumn{2}{|c|}{0.81} & \multicolumn{2}{c|}{22.0} \\
\hline Significance & $\mathrm{t}$ & \multicolumn{2}{|c|}{9.41} & \multicolumn{2}{c|}{0.001} \\
\cline { 3 - 6 } & $\mathrm{p}$ & \multicolumn{2}{|c|}{$0.001 *$} & \multicolumn{2}{c|}{0.09} \\
\hline
\end{tabular}

\section{* significant}

The Actual Value of FEV1 (L) in type 2 DM patients was $2.07 \pm 0.50$ (76.1 $\pm 13.6 \%$ of percentage predicted). The Actual Value of FEV1 $(\mathrm{L})$ in controls was $2.95 \pm 0.41$ (102.6 $\pm 11.8 \%$ of percentage predicted). There was a statistically significant decrease in the level of FEV1 in type 2 DM patients compared to healthy adult male controls $(p<0.001)$ The Actual Value of
FEV1/ FVC (\%) in type 2 DM patients was $96.7 \pm 7.7$ (121.2 \pm $9.9 \%$ of percentage predicted). The Actual Value of FEV1/ FVC (\%) in adult controls was $93.5 \pm 5.9$ (110.7 $\pm 8.4 \%$ of percentage predicted). There was a statistically significant increase in the level of ratio of FEV1/ FVC in type 2 DM patients compared to healthy adult male controls $(p<0.001)$ (Table 3$)$

Table 3: comparison of FEV1/FVC between type 2 diabetes mellitus patients and controls

\begin{tabular}{|c|c|c|c|c|c|}
\hline \multirow{2}{*}{ Groups } & \multirow{2}{*}{$\mathrm{n}$} & \multicolumn{2}{|c|}{ Actual range } & \multicolumn{2}{c|}{ Predicted (\%) } \\
\cline { 3 - 6 } & & Range & Mean \pm SD & Range & Mean \pm SD \\
\hline Type 2 DM & 100 & $0.96-3.30$ & $2.07 \pm 0.50$ & $42-115$ & $76.1 \pm 13.6$ \\
\hline Controls & 100 & $1.99-4.10$ & $2.95 \pm 0.41$ & $83-141$ & $102.6 \pm 11.8$ \\
\hline Mean difference & & \multicolumn{2}{|c|}{0.88} & \multicolumn{2}{c|}{26.5} \\
\hline Significance & $\mathrm{t}$ & \multicolumn{2}{|c|}{13.28} & \multicolumn{2}{c|}{0.001} \\
\cline { 2 - 6 } & $\mathrm{p}$ & \multicolumn{2}{|c|}{$0.001 *$} & \multicolumn{2}{c}{$* 0.68$} \\
\hline
\end{tabular}


The Actual Value of FEF $25-75 \%(\mathrm{~L} / \mathrm{Sec})$ in type $2 \mathrm{DM}$ patients was $3.06 \pm 0.84$ ( $80.3 \pm 16.8 \%$ of percentage predicted). The Actual Value of FEF $25-75 \%(\mathrm{~L} / \mathrm{Sec})$ in controls was $4.38 \pm$ 0.79 (103.4 $\pm 19.9 \%$ of percentage predicted). There was a statistically significant decrease in the level of FEF25-75\%in type 2 DM patients when compared to healthy adult male controls $(p<0.001)$.Statistical analysis was done by Students ' $t$ ' test.

\begin{tabular}{|c|c|c|c|c|c|}
\hline \multirow{2}{*}{ Groups } & \multirow{2}{*}{$\mathrm{n}$} & \multicolumn{2}{|c|}{ Actual range } & \multicolumn{2}{|c|}{ Predicted (\%) } \\
\hline & & Range & Mean \pm SD & Range & Mean \pm SD \\
\hline Type 2 DM & 100 & $2.84-12.40$ & $6.36 \pm 1.90$ & $37-138$ & $77.3 \pm 21.4$ \\
\hline Controls & 100 & $4.89-11.97$ & $8.16 \pm 1.19$ & $63-126$ & $91.4 \pm 11.6$ \\
\hline Mean difference & & \multicolumn{2}{|c|}{1.80} & \multicolumn{2}{|c|}{14.1} \\
\hline \multirow[t]{2}{*}{ Significance } & $\mathrm{t}$ & \multicolumn{2}{|c|}{7.78} & \multicolumn{2}{|c|}{5.82} \\
\hline & $\mathrm{p}$ & \multicolumn{2}{|c|}{0.001} & \multicolumn{2}{|c|}{0.001} \\
\hline
\end{tabular}

The percentage predicted of FEF25-75\% (\%) in type 2 DM patients with a FBS level of $90-110 \mathrm{mg} / \mathrm{dl}$ was $84.3 \pm 7.9$. This value was $82.3 \pm 17.8$ in type 2 DM patients with an FBS level of 110-200 mg/dl. In type 2 DM patients with a FBS level of $200-300 \mathrm{mg} / \mathrm{dl}$ FEF25-75\% was $74.3 \pm 15.5$. FEF25-75\% was $71.0 \pm 12.9$ in type 2 DM patients with a FBS level of more than $300 \mathrm{mg} / \mathrm{dl}$. It was observed that the level of FEF $25-75 \%$ slightly decreased with an increase in the level of FBS which was statistically not significant $(p>0.05)$. The percentage predicted of PEFR (\%) in type 2 DM patients with a FBS levelof

\begin{tabular}{|c|c|c|c|c|c|c|}
\hline $\begin{array}{c}\text { FBS } \\
(\mathrm{mg} / \mathrm{dl})\end{array}$ & $\mathrm{n}$ & $\begin{array}{c}\text { FVC } \\
(\% \text { Pred })\end{array}$ & $\begin{array}{c}\text { FEV1 } \\
(\% \text { Pred })\end{array}$ & $\begin{array}{c}\text { FEV1/FVC } \\
(\% \text { Pred })\end{array}$ & $\begin{array}{c}\text { FEF 25 }-75 \%(\% \\
\text { Pred })\end{array}$ & $\begin{array}{c}\text { PEFR } \\
(\% \text { Pred })\end{array}$ \\
\hline $90-110$ & 8 & $91.5 \pm 16.5$ & $86.9 \pm 19.0$ & $120.8 \pm 10.8$ & $84.3 \pm 7.9$ & $99.6 \pm 24.6$ \\
\hline $111-200$ & 67 & $68.4 \pm 13.7$ & $76.4 \pm 11.9$ & $121.6 \pm 7.3$ & $82.3 \pm 17.8$ & $76.9 \pm 19.6$ \\
\hline $200-300$ & 21 & $67.9 \pm 17.2$ & $70.1 \pm 14.4$ & $119.7 \pm 14.0$ & $74.3 \pm 15.5$ & $733.9 \pm 21.0$ \\
\hline$>300$ & 4 & $76.8 \pm 9.6$ & $81.5 \pm 12.9$ & $122.3 \pm 21.1$ & $71.0 \pm 12.9$ & $56.0 \pm 17.0$ \\
\hline ANOVA & $\mathrm{t}$ & 6.40 & 3.46 & 0.21 & 1.77 & 4.92 \\
\cline { 2 - 7 } & $\mathrm{p}$ & $0.01 *$ & $0.05 *$ & 0.89 & 0.16 & 0.001 \\
\hline
\end{tabular}

\section{Discussion}

The lung is considered as a 'target organ' indiabetes mellitus.This study was done to analyze the effects of chronic diabetes on pulmonary functions of type 2DM compared with normal of same age group. In our study, there was a statistically significant decrease in the level of FVC in type 2 DM patients compared to healthy male subjects. It is also shown that level of FVC decreases more with an increase in the duration of type 2 diabetes mellitus, with an increase in the level of FBS and PPBS. Similar findings were reported from Robert WE et al; ${ }^{[7]}$ Wendy DA et al,[8] Timothy DM et al; ${ }^{[9]}$, and Meo SA et al; [10]
The Actual Value of PEFR (L/Sec) in type 2 DM patients was Value of PEFR (L/Sec) in controls was $8.16 \pm 1.19$ (91.4 $\pm 11.6 \%$ of percentage predicted). There was a statistically significant to healthy adult male controls $(P<0.001)$ (Table 4)

Table 4: comparison of PEFR between type 2 diabetes mellitus patients and controls

$90-110 \mathrm{mg} / \mathrm{dl}$ was $99.6 \pm 24.6$. This value was $76.9 \pm 19.6$ in type 2 DM patients with FBS levels of $110-200 \mathrm{mg} / \mathrm{dl}$. In type 2 DM patients with FBS level of 200-300 mg/dl, PEFR was 73.9 \pm 21.0. PEFR was $56.0 \pm 17.0$ in type $2 \mathrm{DM}$ patients with a FBS level of more than $300 \mathrm{mg} / \mathrm{dl}$. It was observed that the level of PEFR decreased with an increase in the level of FBS which was statistically significant $(p<0.01)$ (Table 5)

Table 5: Comparison of pulmonary function parameters with relation to FBS level in type 2 diabetes mellitus patients 6.36 ? 1.90 ( $77.3 \pm 21.4 \%$ of percentage predicted). The Actual decrease in the level of PEFR in type 2 DM patients compared 
FBS and PPBS. Similar findings were reported from other studies in this field. ${ }^{[7-10]}$ In diabetes mellitus thickening of the alveolar epithelium and pulmonary capillary basal lamina occurs leading to pulmonary microangiopathy and reduced pulmonary elastic recoil caused by nonenzymatic glycosylation of the connective tissue which also reduces the FEV1 in diabetes mellitus. ${ }^{[6]}$ In our study, there was a statistically significant increase in the level of ratio ofFEV1/FVC. Type 2 DM patients showed an increase of $10.5 \%$ when compared tohealthy adult male subjects. It shows that the ratio of FEV1/FVC was not significantlyincreased with an increase in the duration of type 2 diabetes mellitus and with an increase in the level of FBS and PPBS, which was statistically not significant $(p>0.05)$.In this study, the level of forced expiratory flow rate between $25 \%$ and $75 \%$ of FVC or average forced expiratory flow rate was reduced by $1.32 \mathrm{~L} / \mathrm{sec}$ in type $2 \mathrm{DM}$ patients compared to healthy adult male subjects. This reduction is statistically significant. It was also observed that level of FEF25-75\% decreased significantly more with an increase in the duration of type 2 diabetes mellitus and slightly decreased with an increase in the level of FBS and PPBS. A similar study was reported from Sreeja CK et al; ${ }^{[11]}$ which showed a reduction in FEF25-75\% $2.45 \pm 0.55$ in the diabetic study group and $2.82 \pm$ 0.70 in controls. The initial part of the expiratory FVC curve, FEF25-75\% depends upon non-bronchopulmonary factors like neuromuscular and mechanical factors of inertialdistortion of lungs. ${ }^{[7]}$ The PEFR results showed a statistically significant decrease in the level of PEFR (14.1\%of percentage predicted). It has also shown that the PEFR decreases more with an increase in the duration of type 2 diabetes mellitus and with an increase in the level of FBS and PPBS. These findings were similar to those reported by Meo SA et al; ${ }^{[10]}$ and Sreeja CK et al; ${ }^{[11]}$. The reduced flow rate is due to a reduction in the forcegenerating capacity of expiratory muscles, higher airway resistance, reduced recoiling nature of lung and thorax, and decrease in muscle strength. ${ }^{[8]} \mathrm{As}$ it is shown in our study, the parameters of pulmonary functions FVC, FEV1, FEF25-75\%, and PEFR which are analyzed and showed a decrease in their value, in type $2 \mathrm{DM}$ patients compared to healthy adult subjects. There is a decrease in FVC,FEV1, FEF25-75\%, and PEFR value with an increase in the duration of type 2 diabetesmellitus. The FEV1/FVC ratio shows a slight increase in its value. These findingscorrelate with the findings of other similar studies. ${ }^{77-}$ ${ }^{9}$ It shows that the effect is very much dependent upon the extent of exposureboth duration-wise, levels of FBS, and PPBS wise in type 2 diabetes mellitus. Themechanisms responsible for these airway effects are changes in the pulmonaryconnective tissue and microvasculature due to diabetes mellitus. Which leads to thethickening of the alveolar epithelium and capillary endothelial basement membranes.

\section{Conclusion}

This study found the pulmonary functions FVC, FEV1, FEF $25 \%-75 \%$, and PEFR are decreased inType 2 diabetes mellitus compared to controls. FEV1/FVC\% slightly increased in Type 2 diabetes mellitus, which is indicative of the restrictive pulmonary disorder. The above-mentioned effects of Type 2 diabetes mellitus on pulmonary functions are probably aconsequenceof alterations in pulmonary connective tissue, thickening of the basement membrane of capillary and alveolus, modification of surfactant, decreased recoiling tendency of the lung and decreased muscle endurance.

\section{REFERENCES}

1. Sushruta Samhita BD. 1-3 Calcutta,1907-16.

2. Expert committee on the diagnosis and classification of diabetes mellitus. Report of the expert committee on the diagnosis and classification of Diabetes mellitus. Diabetic Care, Suppl. 1, 2003; S5-S20.

3. Leahy JL. Beta-cell dysfunction in type 2 diabetes mellitus. In Khan RC editorsJoslin's Diabetes Medicine. 14th ed, 2005; 449-61.

4. Larsen, Kronenberg, Melmed, Polonsky. Williams textbook endocrinology. 10thed.Pennsylvania: Elsevier India Publisher 2003.

5. Carlos BA, Stern E, Kramer M, Lebzelter J, Blum I, Fink G. Pulmonary function in patients with diabetes mellitus. Am J Med Sci 2001;322(3):127-32.

6. Malcom S. Is the lung a target organ in diabetes mellitus? Arch Intern Med1990;150:1385-88.

7. Robert WE, Beiser A, Rachel J, Givelber, George T, O'Connor et al. Associationbetween glycemic state and lung function. Am J Respir Crit Care Med2003;167:911916.

8. Wendy DA, Knuiman M, Kendell P, Grange V, Davis TME. Glycemic exposureis associated with reduced pulmonary function in Type-2 diabetes. Diabetes Care2004;27:752757.

9. Timothy DM, Knuiman $M$, Kendell $P, V u ~ H$, Davis WA. Reduced pulmonaryfunction and its associations in type 2 diabetes: Diabetes Res Clin Pract2000;50:152-159.

10. Meo SA, Drees AMA, Ahmed J, Shah SFA, Al-R K, Husain $A, A l-R u b e n$ K. Effect of the duration of disease on ventilatory function in an ethnic Saudi group of diabetic patients. J Diabetics Sci Technol 2007;1(5):711-17.

11. Sreeja CK, Samuel E, Chandran CK, Shashidaran S. Pulmonary function in patients with diabetes mellitus. IJPP 2003;47(1):87-93.

How to cite this article : Gautam R. A Comparative Study of Pulmonary Functions in Patients with Type 2 Diabetes Mellitus and Normal Individuals.Perspectives in Medical Research 2021; 9 (1):59-63 DOI:10.47799/pimr.0901.12

Sources of Support: Nil, Conflict of interest: None declared 